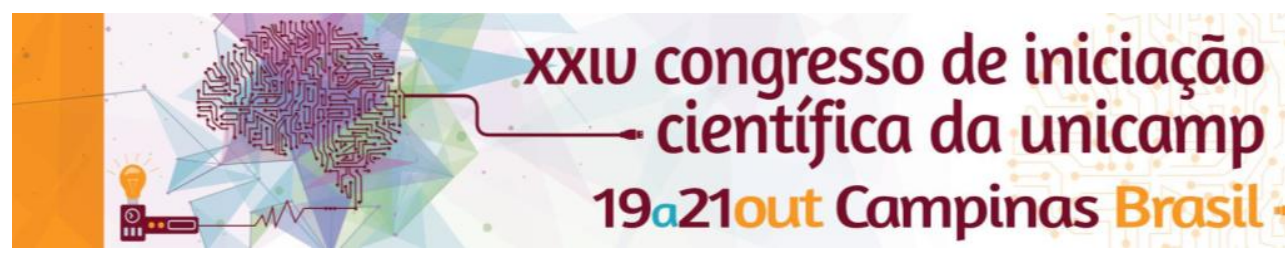

\title{
Avaliação das propriedades mecânicas e mucoadesão de géis poliméricos termorreversíveis
}

\author{
para liberação bucal de ibuprofeno.
}

\author{
Stephany di Carla Santos*, Susan Grahl, Bruno V. Muniz, Daniele R. de Araújo, Michelle F. M. Braga Leite
}

\begin{abstract}
Resumo
Um grande número de medicamentos anti-inflamatórios, como o lbuprofeno, está à disposição da classe médica e odontológica para controlar ou reduzir a inflamação e a dor. O uso tópico pode apresentar um aumento da disponibilidade no sítio de ação evitando efeitos adversos do uso sistêmico. Recentemente, um material que tem despertado cada vez mais interesse para aplicações biomédicas, incluindo liberação controlada de fármacos é o gel a base de polaxamer. Dentro deste contexto o presente projeto buscou avaliar in vitro as propriedades mecânicas e capacidade de mucoadesão de géis poliméricos termorreversíveis contendo diferentes polímeros (carbopol e goma xantana) para liberação bucal de ibuprofeno visando o uso tópico em mucosa oral na área de Odontologia.
\end{abstract}

\section{Palavras-chave}

Ibuprofeno, drug delivery, mucoadesão, geis poliméricos, Odontologia

\section{Introdução}

Ibuprofeno é um agente anti-inflamatório não esteroide de ação moderada altamente utilizado em Odontologia ${ }^{1}$. O seu uso tópico em mucosa oral em um sistema de "drug delivery" (liberação sustentada) pode apresentar vantagens como aumento da disponibilidade no sítio de ação evitando efeitos adversos do seu uso sistêmico, com os distúrbios gastrintestinais (náusea, vômito, dor epigástrica, etc), dentre outros. Poloxamers são copolímeros, formados por unidades de óxido de etileno (OE) e óxido de propileno (OP) e apresentam capacidade de transição solução-gel quando chegam próximo a temperatura corporal. Este sistema de liberação, além de promover a liberação prolongada de agentes farmacológicos, mostraram melhora nas propriedades biofarmacêuticas, farmacodinâmicas e farmacocinéticas dos mesmos ${ }^{2}$. O objetivo deste trabalho foi avaliar o efeito de diferentes polímeros (géis híbridos com carbopol e goma xantana) nas propriedades mecânicas (dureza, compressibilidade, elasticidade e adesividade) e na capacidade de mucoadesão (força de destacamento e trabalho de mucoadesão) de géis termorreversíveis à base de poloxamer 407 a 20\% (PL407); PL407 + Goma Xantana (0,15\%) (PL407+GX); e PL407 + Carbopol Ultrez $(1 \%)(P L 407+C)$ para o uso tópico em mucosa oral na área de Odontologia. Os experimentos foram realizados em um equipamento analisador de textura. $O$ ensaio de mucoadesão foi realizado em mucosa jugal fresca de suínos.

\section{Resultados e Discussão}

A Tabela 1 mostra a média $( \pm D P)$ das propriedades mecânicas das formulações avaliadas.

\begin{tabular}{cccccc}
\hline $\begin{array}{c}\text { Formul } \\
\text { ação }\end{array}$ & $\begin{array}{c}\text { Durez } \\
\mathbf{a} \\
\mathbf{( N )}\end{array}$ & $\begin{array}{c}\text { Compressib } \\
\text { ilidade } \\
\mathbf{( N . m m )}\end{array}$ & $\begin{array}{c}\text { Coesivi } \\
\text { dade }\end{array}$ & $\begin{array}{c}\text { Elastici } \\
\text { dade }\end{array}$ & $\begin{array}{c}\text { Adesivi } \\
\text { dade } \\
\text { (N.mm) }\end{array}$ \\
\hline PL407 & $\begin{array}{c}0,24 \pm 0 \\
, 04\end{array}$ & $0,85 \pm 0,13$ & $\begin{array}{c}0,96 \pm 0,0 \\
3^{*}\end{array}$ & $0,98 \pm 0$, & $0,33 \pm 0,1$ \\
& & & & 01 & 0
\end{tabular}

\begin{tabular}{cccccc}
$P L 407+$ & $0,33 \pm 0$ & $1,26 \pm 0,22$ & $0,86 \pm 0,0$ & $0,96 \pm 0$, & $0,37 \pm 0,2$ \\
$G X$ &, 09 & 3 & 05 & 1 \\
$P L 407+$ & $0,49 \pm 0$ & $1,47 \pm 0,34^{a * *}$ & $0,82 \pm 0,0$ & $0,91 \pm 0$, & $0,40 \pm 0,3$ \\
$C$ &, $18^{*}$ & & 7 & 08 & 3 \\
\hline
\end{tabular}

ANOVA/Tukey-Kramer. ${ }^{*} p<0,05 ;{ }^{* *} p<0,01$. a- PL407+C vs. PL407
As formulações PL407 e PL407+GX apresentaram melhores desempenhos nas propriedades mecânicas com menores valores de dureza e compressibilidade. No entanto, as formulações não diferiram em relação à elasticidade e adesividade.

A tabela 2 mostra a média ( $\pm \mathrm{DP})$ das propriedades mucoadesivas das formulações avaliadas.

\begin{tabular}{ccc}
\hline Formulação & $\begin{array}{c}\text { Força de } \\
\text { destacamento (N) }\end{array}$ & $\begin{array}{c}\text { Trabalho de } \\
\text { mucoadesão (N/mm) }\end{array}$ \\
\hline$P L 407$ & $0,01 \pm 0,02$ & $0,20 \pm 0,10$ \\
$P L 407+G X$ & $0,11 \pm 0,05$ & $0,29 \pm 0,13$ \\
$P L 407+C$ & $0,11 \pm 0,02$ & $0,34 \pm 0,02$ \\
\hline
\end{tabular}

ANOVA/Tukey-Kramer.

As formulações não apresentaram diferença entre si na força de destacamento, mas a PL407+GX e PL407+C apresentaram maior trabalho de mucoadesão em relação à PL407.

\section{Conclusões}

A adição de goma xantana foi eficiente em melhorar as propriedades mecânicas e de mucoadesão do PL407, tornando essa formulação promissora para futuros estudos in vivo.

\section{Agradecimentos}

Apoio FAPESP - bolsa de Iniciação Científica (\#2015/14783-2) e Auxílio Financeiro (\#2012/06974-4).

1. Bailey, E., Worthington, H. \& Coulthard, P. (2014). Ibuprofen and/or paracetamol (acetaminophen) for pain relief after surgical removal of lower wisdom teeth, a Cochrane systematic review. - Br Dent J 216, 451-5.

2. Batrakova, E. V. \& Kabanov, A. V. (2008). Pluronic block copolymers: evolution of drug delivery concept from inert nanocarriers to biological response modifiers. - J Control Release 130, 98-106. 